\title{
Regional changes in wind energy potential over Europe using regional climate model ensemble projections
}

Article

Published Version

Hueging, H., Haas, R., Born, K., Jacob, D. and Pinto, J. G. (2013) Regional changes in wind energy potential over Europe using regional climate model ensemble projections. Journal of Applied Meteorology and Climatology, 52 (4). pp. 903-917. ISSN 1558-8432 doi: https://doi.org/10.1175/JAMC-D-12086.1 Available at https://centaur.reading.ac.uk/32737/

It is advisable to refer to the publisher's version if you intend to cite from the work. See Guidance on citing.

Published version at: http://dx.doi.org/10.1175/JAMC-D-12-086.1

To link to this article DOI: http://dx.doi.org/10.1175/JAMC-D-12-086.1

Publisher: American Meteorological Society

All outputs in CentAUR are protected by Intellectual Property Rights law, including copyright law. Copyright and IPR is retained by the creators or other copyright holders. Terms and conditions for use of this material are defined in the End User Agreement.

www.reading.ac.uk/centaur 
Central Archive at the University of Reading

Reading's research outputs online 


\title{
Regional Changes in Wind Energy Potential over Europe Using Regional Climate Model Ensemble Projections
}

\author{
Hanna Hueging, Rabea HaAs, And Kai Born \\ Institute for Geophysics and Meteorology, University of Cologne, Cologne, Germany \\ DANIELA JACOB \\ Climate and Service Center, Hamburg, Germany \\ JOAQUIM G. PINTO \\ Institute for Geophysics and Meteorology, University of Cologne, Cologne, Germany
}

(Manuscript received 30 March 2012, in final form 28 September 2012)

\begin{abstract}
The impact of climate change on wind power generation potentials over Europe is investigated by considering ensemble projections from two regional climate models (RCMs) driven by a global climate model (GCM). Wind energy density and its interannual variability are estimated based on hourly near-surface wind speeds. Additionally, the possible impact of climatic changes on the energy output of a sample 2.5-MW turbine is discussed. GCM-driven RCM simulations capture the behavior and variability of current wind energy indices, even though some differences exist when compared with reanalysis-driven RCM simulations. Toward the end of the twenty-first century, projections show significant changes of energy density on annual average across Europe that are substantially stronger in seasonal terms. The emergence time of these changes varies from region to region and season to season, but some long-term trends are already statistically significant in the middle of the twenty-first century. Over northern and central Europe, the wind energy potential is projected to increase, particularly in winter and autumn. In contrast, energy potential over southern Europe may experience a decrease in all seasons except for the Aegean Sea. Changes for wind energy output follow the same patterns but are of smaller magnitude. The GCM/RCM model chains project a significant intensification of both interannual and intra-annual variability of energy density over parts of western and central Europe, thus imposing new challenges to a reliable pan-European energy supply in future decades.
\end{abstract}

\section{Introduction}

The reduction of greenhouse gas (GHG) emissions to mitigate climate change implications has been a crucial topic in recent years (Solomon et al. 2007). Within this context, it is highly desirable to increase the share of electricity generation from regenerative sources like wind and reduce the production from fossil sources. Recently, new wind turbines have been developed and installed, and a large number of offshore wind farms are currently under construction. Wind energy production potential can be quantified by wind energy density (WED), which

Corresponding author address: Joaquim G. Pinto, Institute for Geophysics and Meteorology, University of Cologne, Kerpener Str. 13, 50937 Cologne, Germany.

E-mail: jpinto@meteo.uni-koeln.de is mainly a function of the cube of the wind speed (Manwell et al. 2009). In 2011, the installed capacity of wind power plants in the European Union (EU) amounted to $94 \mathrm{GW}$ (Wilkes et al. 2012). Under current capacity factors, energy output from existing wind power plants meets only approximately $6.3 \%$ of the EU's electricity demand. The European Commission aims at increasing the share of electricity from wind resources to $15.7 \%$ by 2020 (Moccia et al. 2011). Energy supply from wind is related to climate, as wind resources are determined by atmospheric circulation. The most important semipermanent pressure cells over the North Atlantic Ocean basin are the Azores high and the Icelandic low, which induce a large-scale north-south pressure gradient and thus lead to a predominance of westerly winds over the North Atlantic and western Europe. 
TABLE 1. Model names and expansions.

\begin{tabular}{ll}
\hline \hline Climate model name & \multicolumn{1}{c}{ Expansion } \\
\hline CMIP3, CMIP5 & Coupled Model Intercomparison Project Phase 3, Phase 5 \\
COSMO-CLM & Consortium for Small Scale Modelling Climate Limited Area Model \\
ECHAM5/MPI-OM & ECHAM5/Max Planck Institute Ocean Model \\
HadCM3 & Third climate configuration of the Met Office Unified Model \\
PRECIS RCM & Providing Regional Climates for Impacts Studies RCM \\
RCA3 & Third release of the Rossby Centre Regional Climate model \\
REMO & Regional Model \\
\hline
\end{tabular}

Previous studies show that atmospheric circulation and pressure patterns across the North Atlantic and Europe might change under future climate conditions (e.g., Demuzere et al. 2009). Donat et al. (2010) found that an ensemble mean of multiple global climate models (GCMs) projects changes in atmospheric surface pressure over the eastern North Atlantic and Europe, leading to a stronger north-south pressure gradient. Further, Räisänen et al. (2004) and Kjellström et al. (2011) provided evidence that both mean wind speeds over Europe and, particularly, their seasonality may change. However, results for mean wind speed only provide an insight to the sign of the climate trend for wind energy potential but do not allow quantifying the magnitude of the change. Studies that investigate wind energy potential are currently only available for parts of Europe, focusing on the British Isles, North Sea, and Scandinavia and/or the Baltic Sea, and consider both dynamical and empirical downscaling approaches (e.g., Barstad et al. 2012; Pryor et al. 2005, 2012a,b; Pryor and Schoof 2010). Most of these analyses agree on an increase in WED in northern Europe and/or the Baltic region, especially in wintertime. Furthermore, Pryor et al. (2006, 2012a) investigated the interannual variability of wind energy potential under future climate conditions. Pryor et al. (2006) assumed no substantial changes in the level of year-to-year variability using the model HadCM3, whereas Pryor et al. (2012a) found a slight decline in interannual variability in northern Europe. Bloom et al. (2008) analyzed WED changes in the Mediterranean region using the regional climate model (RCM) PRECIS driven by HadCM3 (see Table 1 for a list of climate models). They found a decrease of mean WED, except for the Aegean, where an increase is projected. Pryor et al. (2012a) pointed out that marked differences may exist between RCM runs with the same large-scale GCM forcing, and that internal variability and initial conditions may also have a strong impact on the results. A possible critical factor for such studies is the model resolution, which also has a strong impact on the wind climatology, which may even be of the order of magnitude of the climate change signal (Pryor et al. 2012b).
The first objective of this study is to provide the first pan-European projection of WED for future decades using temporal and spatial high-resolution data. Two GCM-driven RCMs are used. Future projections for energy output of a sample turbine $\left(E_{\text {out }}\right)$ are also assessed. The second objective is to analyze how far both interannual and intra-annual variability of WED and $E_{\text {out }}$ may change in regional terms. Such an assessment is of pivotal importance for future strategic planning of energy networks. In particular, the emergence time of the projected WED changes is investigated. Finally, the dynamical causes for the detected changes in WED and $E_{\text {out }}$ are analyzed.

The present paper is organized as follows. The subsequent section presents the applied data and methods. In section 3 , the ability of the model chain to simulate current wind energy indices is evaluated. Section 4 presents and discusses the results for climate change projections. The emergence time of possible WED changes is analyzed in section 5, while the links to changes in the large-scale atmospheric conditions are discussed in section 6. A short summary and conclusion complete this paper.

\section{Data and methods}

In the present study, we consider simulations with GCM/RCM model chains for recent and future climate conditions. The coupled atmospheric-ocean model ECHAM5/MPI-OM (hereinafter ECHAM; Jungclaus et al. 2006) delivers boundary conditions for the RCMs to simulate the effects of rising GHG concentrations. Pinto et al. (2007), Löptien et al. (2008), and Demuzere et al. (2009) show that ECHAM simulations for recent climate conditions produce mean sea level pressure (MSLP) patterns and synoptic activity in the midlatitudes that are comparable to those of reanalysis data. In the present study, ECHAM climate projections, following the A1B scenario in the Special Report on Emission Scenarios (SRES; Nakicenovic and Swart 2000) are evaluated.

Two different RCMs are considered in this study: 1) COSMO CLM (hereinafter CCLM; Steppeler et al. 2003; Rockel et al. 2008), a nonhydrostatic community 
TABLE 2. List of RCM simulations, spatial resolution, large-scale forcing, members of ECHAM used (out of 3), considered period, and model run details. The ECHAM climate projections for future climate conditions follow the A1B scenario in SRES (Nakicenovic and Swart 2000).

\begin{tabular}{|c|c|c|c|c|c|}
\hline Acronym & Resolution & Forcing & Run & Period & Model run details \\
\hline REMO-20C & $0.44^{\circ} \times 0.44^{\circ}$ & ECHAM-20C & 1,2 & $1961-2000$ & $\begin{array}{l}\text { REMO Climate of the 20th Century run, IPCC Project, } 0.44^{\circ} \\
\text { resolution, 1-h data "REMO_IPCC044_C20_1_R001500_1H" } \\
\text { and "REMO_IPCC044_C20_2_R001504_1H" by D. Jacob in } \\
2005 \text { are available from the World Data Center for Climate } \\
\text { at http://cera-www.dkrz.de/WDCC/ui/Compact.jsp? acronym = } \\
\text { REMO_IPCC044_C20_1_R001500_1H (run 001500), and from } \\
\text { D. Jacob (Climate Service Center) upon request (run 001504). }\end{array}$ \\
\hline REMO-A1B & $0.44^{\circ} \times 0.44^{\circ}$ & ECHAM-A1B & 1,2 & $2061-2100$ & $\begin{array}{l}\text { REMO A1B Scenario Run, IPCC Project, } 0.44^{\circ} \text { resolution, 1-h } \\
\text { data "REMO_IPCC044_A1B_1_R001501_1H" and "REMO_ } \\
\text { IPCC044_A1B_2_R001506_1H" by D. Jacob in } 2005 \text { are } \\
\text { available from the World Data Center for Climate at } \\
\text { http://cera-www.dkrz.de/WDCC/ui/Compact.jsp? acronym = } \\
\text { REMO_IPCC044_A1B_1_R001501_1H (run 001501) and from } \\
\text { D. Jacob (Climate Service Center) upon request (run 001506). }\end{array}$ \\
\hline REMO-ERA & $0.44^{\circ} \times 0.44^{\circ}$ & ERA-40 & - & $1961-2000$ & $\begin{array}{l}\text { REMO ERA-40 Reanalysis Run, IPCC Project, } 0.44^{\circ} \text { resolution, } \\
\text { run 001037, 1-h data "REMO_IPCC044_ERA40_R001037_1H" } \\
\text { by D. Jacob in } 2005 \text { is available from D. Jacob (Climate Service } \\
\text { Center) upon request. }\end{array}$ \\
\hline CCLM-20C & $0.2^{\circ} \times 0.2^{\circ}$ & ECHAM-20C & 1,2 & $1961-2000$ & $\begin{array}{l}\text { Climate Simulation with CLM, Climate of the 20th Century, } \\
\text { Data Stream 3: European region MPI-M/MaD by } \\
\text { M. Lautenschlager et al. from } 2009 \text { is available from the World } \\
\text { Data Center for Climate at doi:10.1594/WDCC/CLM_C20_1_ } \\
\text { D3 (run 1), and doi:10.1594/WDCC/CLM_C20_2_D3 (run 2). }\end{array}$ \\
\hline CCLM-A1B & $0.2^{\circ} \times 0.2^{\circ}$ & ECHAM-A1B & 1,2 & $2061-2100$ & $\begin{array}{l}\text { Climate Simulation with CLM, Scenario A1B, Data } \\
\text { Stream 3: European region MPI-M/MaD by M. Lautenschlager } \\
\text { et al. from } 2009 \text { is available from the World Data Center for } \\
\text { Climate at doi:10.1594/WDCC/CLM_A1B_1_D3 (run 1), } \\
\text { and doi:10.1594/WDCC/CLM_A1B_2_D3 (run 2). }\end{array}$ \\
\hline CCLM-ERA & $0.2^{\circ} \times 0.2^{\circ}$ & ERA-40 & - & $1961-2000$ & $\begin{array}{l}\text { CLM HYDROCARE 20th Century Reconstruction run } 0.165^{\circ} \\
\text { Data Stream. PIK_CLM4.0_0165L32_hydrocare_ERA40_20C } \\
\text { by U. Böhm in } 2007 \text { is available from the Potsdam Institute for } \\
\text { Climate Impact Research, Potsdam, Germany, upon request. }\end{array}$ \\
\hline
\end{tabular}

development based on the Deutscher Wetterdienst numerical weather prediction model COSMO; and 2) REMO (Jacob 2001), a hydrostatic model developed at the Max Planck Institute for Meteorology (MPI-M) in Hamburg, Germany. Two 40-yr periods are compared to quantify potential changes in energy potential across Europe: 1) recent climate conditions [twentieth-century (20C) scenario, 1961-2000], and 2) future climate conditions (A1B scenario, 2001-2100). For all investigations except section 5, focus is given to the periods 1961-2000 and 2061-2100. For these two periods, ensemble simulations are pooled together for evaluation, resulting in 80-yr time series. Internal variability is assessed by comparing the results of different RCM ensemble members (40 years each), which are driven by atmospheric data from different GCM ensemble runs. For the purpose of validation, ECHAM-driven RCM simulations for current climate are compared with 40-yr European Centre for Medium-Range Weather Forecasts Re-Analysis (ERA40; Uppala et al. 2005)-driven simulations with similar setups (cf. Table 2). The choice of using ERA-40-driven RCM simulations instead of ERA-Interim (Dee et al. 2011)-driven RCM runs was motivated by the availability of high-resolution data from evaluated multidecadal RCM simulations. The same reasoning applies for CMIP3 (Meehl et al. 2007) against CMIP5 runs (Taylor et al. 2012).

Both RCMs have been previously evaluated and their output has been compared with observational data. Walter et al. (2006) provide evidence that REMO and CCLM are able to reproduce both the temporal and spatial variability of wind observations in Germany. Deviations between reanalysis-driven RCMs and observations generally do not exceed $1 \mathrm{~m} \mathrm{~s}^{-1}$. Larger deviations are found only in areas with strong structured terrain and in exposed areas, because the RCM topography is too smooth (Walter et al. 2006). In a comprehensive evaluation of the CCLM, Hollweg et al. (2008) find that reanalysis-driven CCLM simulations have a positive bias of about $0.6 \mathrm{~m} \mathrm{~s}^{-1}$ relative 
to observations for 10-yr annual average wind speeds in Germany. Between reanalysis-driven simulations and ECHAM simulations of CCLM, deviations are below $0.5 \mathrm{~m} \mathrm{~s}^{-1}$ for onshore areas, but may reach up to $1 \mathrm{~m} \mathrm{~s}^{-1}$ for offshore areas. Larsén et al. (2010) compare REMO results with satellite data for offshore areas and conclude that REMO is also able to reproduce wind speeds over the North Sea. The authors conclude that the RCM is suitable for wind energy assessments.

RCM output for hourly $10-\mathrm{m}$ wind speed forms the basis of the present analysis. The high spatial and temporal resolution of the wind data allows avoidance of any considerations regarding data distribution. Following Manwell et al. (2009), mean WED $\bar{E}$ is computed from time series of wind velocities $U_{i}$ in a time span $N$ :

$$
\bar{E}=\left(\frac{1}{2}\right) \rho \frac{1}{N} \sum_{i=1}^{N} U_{i}^{3} .
$$

Standard conditions are assumed for air density $\rho$ with a constant value of $1.225 \mathrm{~kg} \mathrm{~m}^{-3}$. The coefficient of variation, estimated by the ratio between the standard deviation of annual mean WED and the overall mean of the 40-yr period, is used as index for interannual variability. The high temporal resolution (hourly data) facilitates the calculation of mean WED directly from series of wind speeds and provides accurate WED results. In a second step, wind velocities $U$ are extrapolated from $10 \mathrm{~m}\left(z_{r}\right)$ to $80 \mathrm{~m}(z)$, which is the current average hub height of onshore wind turbines (EEA 2009). As common practice, the power law is used:

$$
\frac{U(z)}{U\left(z_{r}\right)}=\left(\frac{z}{z_{r}}\right)^{\alpha} .
$$

Following international standards for wind turbine design provided by the International Electrotechnical Commission (IEC), power-law exponents $\alpha$ of 0.2 for onshore areas (IEC 2005a) and of 0.14 for offshore sites (IEC 2005b) are used in this study. The quantity $E_{\text {out }}$ is computed from the wind velocities in $80 \mathrm{~m}$. Wind turbine characteristics are assumed as following a 2.5-MW wind turbine from the General Electric Co., Inc. (General Electric 2010):

1) There is no energy output below cut-in wind velocity $\left(3.5 \mathrm{~m} \mathrm{~s}^{-1}\right)$ and above cut-out wind velocity $\left(25 \mathrm{~m} \mathrm{~s}^{-1}\right)$.

2) Between cut-in wind velocity $\left(3.5 \mathrm{~m} \mathrm{~s}^{-1}\right)$ and rated wind velocity $\left(12.5 \mathrm{~m} \mathrm{~s}^{-1}\right)$ the power output is proportional to the wind velocity as

$$
E_{\text {out }}=C_{p} \frac{1}{2} \rho \pi R^{2} U^{3},
$$

with a constant power coefficient $C_{p}$ of 0.35 and a rotor radius $R$ of $50 \mathrm{~m}$.

3) There is maximum energy output (2.5 MW) between rated wind velocity $\left(12.5 \mathrm{~m} \mathrm{~s}^{-1}\right)$ and cut-out wind velocity $\left(25 \mathrm{~m} \mathrm{~s}^{-1}\right)$.

In this study, we have analyzed all four seasons. However, in the following, we focus on winter [DecemberFebruary (DJF)] and summer [June-August (JJA)], where evaluated changes associated with increasing GHG forcing are large and reflect characteristic changes observed in all seasons (see sections 4 and 5). Interannual variability of WED and $E_{\text {out }}$ is calculated respectively as $\sigma / \bar{E}$ and $\sigma / \bar{E}_{\text {out }}, \sigma$ being the standard deviation of the annual time series. The results of the RCMs are compared regarding boundary conditions (20C versus ERA forcing), internal variability (run 1 versus run 2 for ECHAM forcing), and RCM architecture (REMO versus CCLM, both with same 20C forcing). Following Schönwiese (1985), differences between datasets are tested with Student's $t$ test (long-term averages) and $F$ test (interannual variability).

\section{Evaluations of present climate runs}

In this section, wind indices in the reference period (1961-2000) are discussed for the purpose of validation. In particular, results for the different model chains are compared to identify model biases and to estimate uncertainties. The sensitivity to boundary conditions from the GCM is evaluated by comparing the ECHAMdriven RCM simulations for the end of the twentieth century (1961-2000, referred to as RCMs-20C) with ERA40 reanalysis-driven simulations (referred to as RCMsERA). When discussing specific results for one of the models, the simulations are referred to as REMO-20C, CCLM-20C, REMO-ERA, and CCLM-ERA. As additional source of deviations, the effect of different RCMs and different realizations of GCM climate scenarios are quantified. As mentioned in chapter 2, long-term averages are compared using 80-yr time series from pooled RCM output, whereas internal variability is analyzed using single ensemble runs of 40-yr length (Tables 3 and 2). This analysis gives an indication over which areas and for which model chains the GCM boundary conditions induce a different climatology than ERA-40 boundary conditions.

Figures $1 \mathrm{a}$ and $1 \mathrm{~b}$ show the results for WED with RCM-20C forcing in annual terms. Some obvious problems occur over orographic structured terrain and high orography. This is particularly the case for REMO, which has a smoother orography and underestimates WED along the major topographical features of Europe 
TABLE 3. Relative RMSDs (\%) between the RCMs-20C and the RCMs-ERA for WED and $E_{\text {out }}$. The RMSD is calculated over the whole study domain; see Fig. 1. Boundary conditions consider the differences between the RCM simulations with ECHAM-20C forcing and those with ERA-40 boundary conditions for the period 1961-2000. Internal variability quantifies the differences between the ensemble runs of the same forcing, e.g., REMO runs using ECHAM-20C runs 1 and 2. RCM architecture considers the differences between the REMO and CCLM with ECHAM-20C boundary conditions. Significant differences are given in boldface font (Student's $t$ test, 95\% confidence level).

\begin{tabular}{lcr}
\hline & WED & $E_{\text {out }}$ \\
\hline & Boundary conditions & \\
Year & $\mathbf{2 2 . 5}$ & $\mathbf{1 5 . 8}$ \\
CCLM & $\mathbf{1 8 . 0}$ & $\mathbf{8 . 7}$ \\
REMO & & \\
Winter & $\mathbf{2 1 . 2}$ & $\mathbf{1 3 . 3}$ \\
CCLM & $\mathbf{1 8 . 2}$ & 7.3 \\
REMO & & \\
Spring & $\mathbf{2 2 . 1}$ & $\mathbf{1 6 . 0}$ \\
CCLM & $\mathbf{1 8 . 2}$ & 7.8 \\
REMO & $\mathbf{3 3 . 9}$ & $\mathbf{2 4 . 7}$ \\
Summer & $\mathbf{3 0 . 4}$ & $\mathbf{1 9 . 2}$ \\
CCLM & $\mathbf{2 9 . 2}$ & \\
REMO & $\mathbf{2 1 . 3}$ & $\mathbf{1 6 . 1}$ \\
Autumn & 5.5 & \\
CCLM & 3.1 & 1.0 \\
REMO & Internal variability & 1.1 \\
CCLM & RCM architecture & $\mathbf{3 5 . 1}$ \\
REMO & & \\
\hline
\end{tabular}

relative to CCLM. Other deviations are found over the Mediterranean Sea, where WED is underestimated. This is associated with a deficient representation of the local wind systems (e.g., bora, etesian winds) in the RCM. In general terms, the regional patterns are well captured by the RCMs-20C in comparison with RCM-ERA forcing. However, WED values are significantly higher for ECHAM forcing over a large part of the domain, particularly for CCLM (Figs. 1c,d).

The sensitivity to boundary conditions varies seasonally in terms of regional patterns (not shown) and in terms of magnitude (Table 3): the largest deviations are observed for summer with circa $30 \%$, while for the other seasons the deviations are around $20 \%$. Demuzere et al. (2009) show that ECHAM features a more pronounced north-south pressure gradient over Europe than ERA40. Particularly during wintertime, the enhanced pressure difference between the Icelandic low and the Azores high leads to stronger westerlies. Similar deviations are found for summertime, when the Azores high is stronger and extends farther east in ECHAM than in ERA-40.
This could contribute to the underestimation of wind energy potential of the RCMs-20C relative to the RCMs-ERA over the Baltic Sea. The biases in the CCLM model chains exhibit a strong land-sea gradient. Over southern Europe, CCLM-20C significantly overestimates WED relative to CCLM-ERA (Fig. 1c). The bias in the REMO model chains is typically smaller here (Fig. 1d). Over northern Europe (i.e., Scandinavia and the Baltic Sea) and the Aegean Sea, REMO-20C underestimates WED by up to $-80 \mathrm{~W} \mathrm{~m}^{-2}$.

In terms of $E_{\text {out }}$, the regional patterns are generally correctly captured by the RCMs-20C (Figs. 1e,f), and the bias to RCMs-ERA is of similar but smaller magnitude (Figs. 1g,h; Table 3). Especially in the REMO model chains, the overall root-mean-square deviation (RMSD) is lower for $E_{\text {out }}$ and in most seasons is less than half the bias of WED (Table 3). This indicates that a considerable part of the deviations between RCM-ERA and RCM-20C simulations is above the wind velocity range usable for wind energy generation. The analysis of internal variability between ensemble runs with the same forcing shows only a minor and nonsignificant sensitivity (RMSD below $6 \%$ for both WED and $E_{\text {out }}$; Table 3). The results for WED and $E_{\text {out }}$ are also sensitive to the choice of RCM. In most onshore regions, the WED is larger in CCLM-20C than in REMO-20C (Figs. 1a,b,e,f). The deviations are most pronounced in mountain regions. With a relative RMSD of $35.1 \%$, the sensitivity to the RCM formulation is larger in terms of $E_{\text {out }}$ than for WED (relative RMSD 28.4\%; Table 3).

Concerning interannual variability of WED and $E_{\text {out }}$, the patterns of the two different RCM realizations are in reasonable agreement, although deviations over Scandinavia and the Mediterranean exist (Figs. 2a,b,e,f). The sensitivity to the boundary conditions is also given for interannual variability of both WED and $E_{\text {out. }}$ (Figs. 2c,d,g,h): in some parts of the study domain, the variability is considerably underestimated (up to $-80 \times$ $10^{-3} \mathrm{MW} \mathrm{h}$ ) in the RCM-20C model chains relative to the RCM-ERA simulations. These differences are, however, significant only over limited parts of the model domain (cf. Figs. 2c,d,g,h). For interannual variability of both WED and $\mathrm{E}_{\text {out }}$ the overall relative RMSD between REMO-20C and REMO-ERA is $19.6 \%$ (Table 4). CCLM has a higher relative RMSD for interannual variability of $E_{\text {out }}$ than of WED (19.7\% versus $\left.17.0 \%\right)$. However, overall deviations to RCM-ERA are not statistically significant. Furthermore, interannual variability is also sensitive to the choice of GCM ensemble member (Table 4, internal variability). Further, both $E_{\text {out }}$ and WED are sensitive to the RCM formulation: the relative RMSD between the RCMs is higher for the interannual variability of $E_{\text {out }}(22.9 \%)$ than for the 

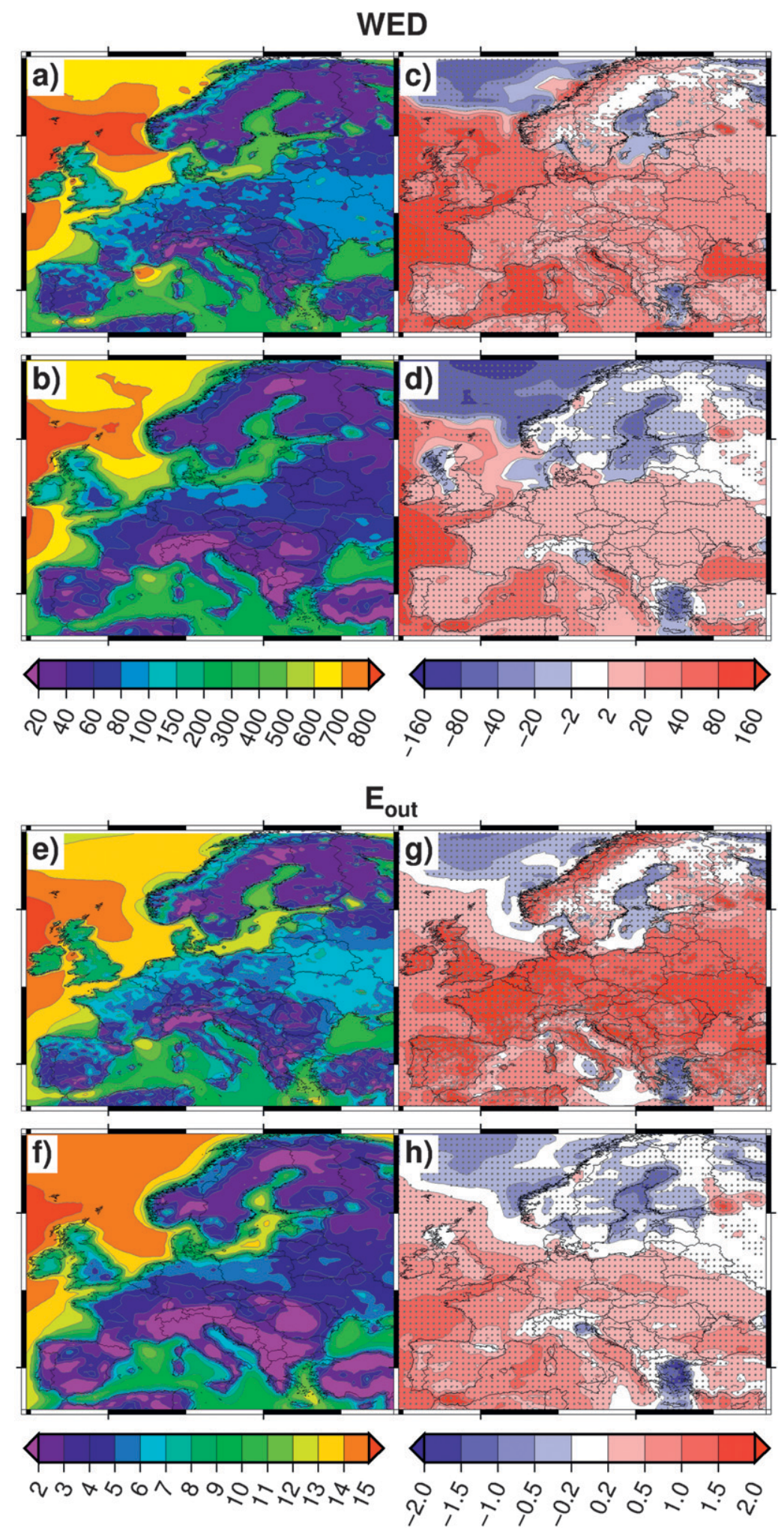

FIG. 1. Annual mean of WED obtained from RCMs-20C $\left(\mathrm{W} \mathrm{m}^{-2}\right)$ for (a) CCLM and (b) REMO. (c),(d) As in (a),(b), but for difference between RCMs-20C and RCMs-ERA. Annual $E_{\text {out }}$ of the sample turbine obtained from RCMs-20C (10 $\left.0^{3} \mathrm{MW} \mathrm{h}\right)$ for (e) CCLM and (f) REMO. (g),(h) As in (e),(f), but for difference between RCMs20C and RCMs-ERA. Reference period is 1961-2000. Significant differences are dotted (Student's $t$ test, 95\% confidence level). 

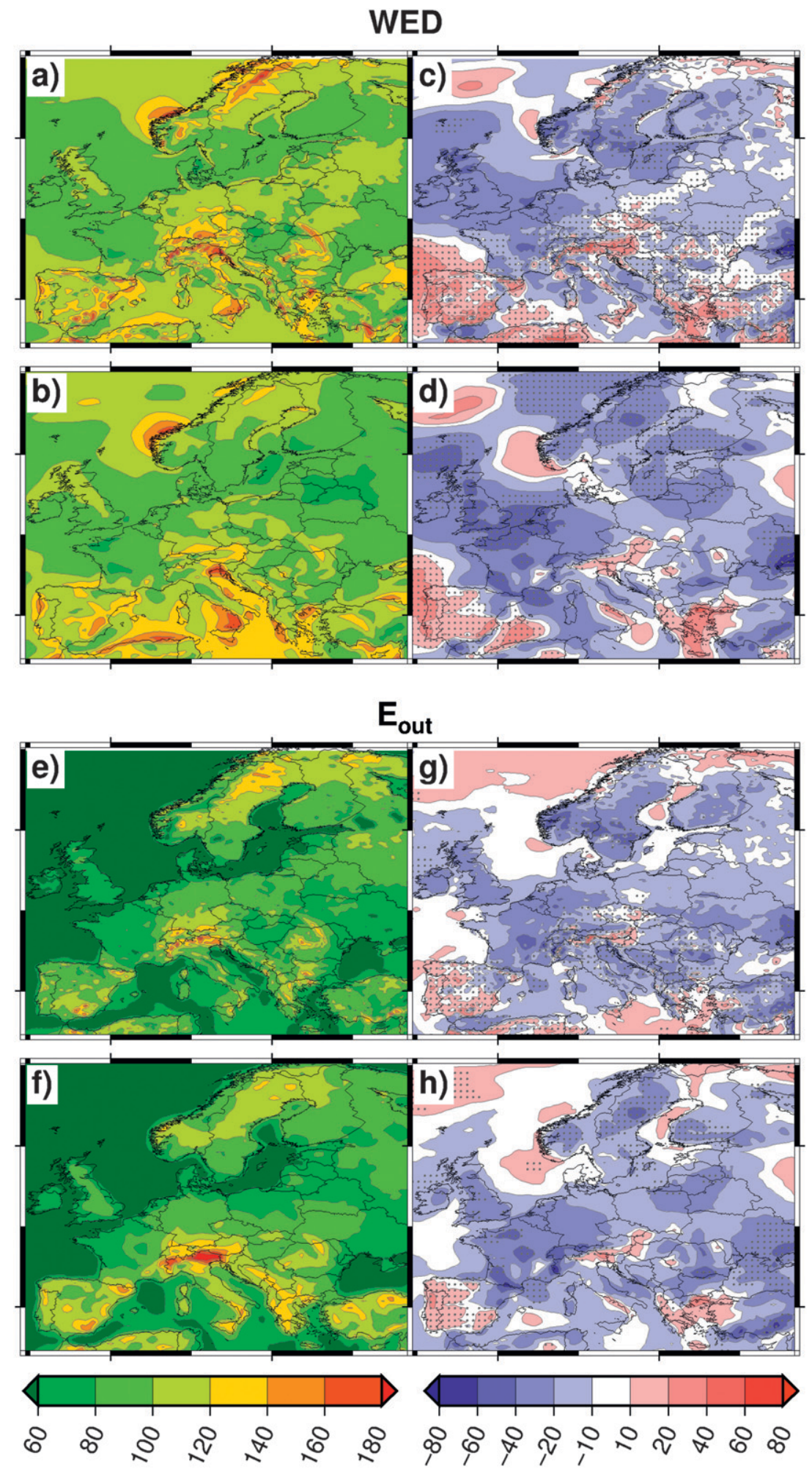

FIG. 2. Interannual variability of WED $(\sigma / \bar{E})$ obtained from RCM-20C $\left(10^{-3} \mathrm{~W} \mathrm{~m}^{-2}\right)$ for (a) CCLM and (b) REMO. (c),(d) As in (a),(b), but for differences between RCMs-20C and RCMs-ERA. Interannual variability of $E_{\text {out }}\left(\sigma / \bar{E}_{\text {out }}\right)$ of the sample turbine obtained from RCMs-20C $\left(10^{-3}\right.$ MW h) for (e) CCLM and (f) REMO. (g),(h) As in (e),(f), but for differences between RCMs-20C and RCMs-ERA. Reference period is 1961-2000. Significant differences are dotted ( $F$ test, $95 \%$ confidence level). 
TABLE 4. As in Table 3, but for the interannual variability of WED and $E_{\text {out }}$. None of the deviations is statistically significant ( $F$ test, $95 \%$ confidence level).

\begin{tabular}{lcc}
\hline \hline & $\begin{array}{c}\text { Interannual } \\
\text { variability of WED }\end{array}$ & $\begin{array}{c}\text { Interannual } \\
\text { variability of } E_{\text {out }}\end{array}$ \\
\hline CCLM & Boundary conditions & \\
REMO & 17.0 & 19.7 \\
& 19.6 & 19.6 \\
CCLM & Internal variability & \\
REMO & 14.1 & 15.5 \\
& 11.6 & 15.5 \\
& RCM architecture & 22.9 \\
\hline
\end{tabular}

variability of WED (14.6\%; Table 4, RCM architecture). Overall, the interannual variability in both WED and $E_{\text {out }}$ is estimated similarly by the two different RCMs. The coincidence between RCM results concerning interannual variability suggests that ECHAM as forcing GCM produces too little "natural" variability. This has to be kept in mind when discussing the uncertainties of power supply caused by natural variability of WED.

\section{Climate change implications}

The projected alterations in mean WED and $E_{\text {out }}$ induced by climate change are now evaluated. First, possible annual and seasonal changes are presented; second, impacts on interannual variability are assessed. The general patterns of wind energy potential over Europe toward the end of the twenty-first century (2061-2100) are similar to those of the reference period (not shown). However, changes can be detected in some regions: annual mean WED (Figs. 3a,b) increases mainly over Central and northern Europe and decreases over the Mediterranean, except for the Aegean region, where an exceptional local maximum can be seen. The changes in WED mostly do not exceed $\pm 10 \%$. CCLM-A1B shows a slightly stronger climate change signal than REMOA1B for several regions, for example, over the Baltic Sea and western Mediterranean. The sensitivity of the climate change implications to the choice of GCM climate scenario ensemble member is low, with only marginal differences between the runs (not shown).

In seasonal terms, changes are more substantial than for the entire year. During winter (Figs. 3c,d), significant positive changes are identified over northern and central Europe in a belt from Ireland to Russia. Most increases can be found within the range from $+10 \%$ to $+20 \%$, but in some regions values reach up to $+25 \%$ (e.g., Great Britain, western Germany, and the White Sea). For eastern Europe, CCLM-A1B (Fig. 3c) projects a higher amplification of mean WED than REMO-A1B (Fig. 3d).
The decline in WED over southern Europe is also more pronounced in winter than for the whole year. Over large regions of the southern Mediterranean Sea, the Po Valley, and eastern Spain, WED is reduced by more than $20 \%$ (Figs. 3c,d).

In summer, the pattern of change is different (Figs. 3e,f). Most of the areas over continental southern and central Europe exhibit a decrease in mean WED. Largest changes are projected by both RCMs-A1B for the Bay of Biscay and the Tyrrhenian Sea, where WED declines between $-15 \%$ and $-30 \%$. The decreases in WED also affect the British Isles, France, and Germany. Together with the rising WED during winter, this indicates that higher intra-annual fluctuations are expected over these areas. Summertime increases in WED are mainly limited to the Baltic Sea, the west coast of Norway, and the Aegean, with the latter exceeding $+25 \%$ for REMOA1B. The present results for mean WED are in line with work by Kjellström et al. (2011), who analyzed changes of near-surface mean wind speeds from the ensemble of six different GCMs downscaled with the RCA3 RCM.

The regional pattern of climate change in $E_{\text {out }}$ of the sample turbine (Figs. $3 g-1$ ) is similar to the change pattern of mean WED (Figs. 3a-f) but is, particularly for offshore regions, of smaller magnitude. For instance, the offshore areas over the Baltic Sea exhibit increases in $E_{\text {out }}$ around $+5 \%$ in annual terms (Figs. $3 \mathrm{~g}, \mathrm{~h}$ ), whereas the WED rises by up to $+15 \%$ (Figs. 3a,b). This indicates that the changes in WED are to a large extent associated with wind speeds not suitable for wind energy generation. Accordingly, the $E_{\text {out }}$ pattern of change for winter (Figs. 3i,j) closely follows the WED results (Figs. 3c,d), only with weaker magnitude. The strongest alterations of $E_{\text {out }}$ are projected for summer, with the Aegean experiencing an increase above $+25 \%$ and declines in the Tyrrhenian Sea exceeding $-20 \%$ and $-25 \%$ in REMOA1B and CCLM-A1B, respectively (Figs. 3k,1). It should be noted that these findings depend on the selected turbine characteristics and that the identified bias in the magnitude of WED imposed additional uncertainty on the $E_{\text {out }}$ results because of the nonlinear relationship between wind speed and $E_{\text {out }}$.

Figures $4 \mathrm{a}$ and $4 \mathrm{~b}$ show the projected development of the interannual variability of WED. Significant changes are mainly limited to western Europe in both RCMs-A1B. Changes range between $+20 \%$ and $+50 \%$ in a sector from the Bay of Biscay to southern Finland, covering both onshore and offshore areas. In most regions, the increase in variability is slightly smaller in REMO-A1B (Fig. 4b) than in CCLM-A1B (Fig. 4a). Different ensemble members of the climate projection reveal slightly different regional characteristics: one ensemble member 
WED
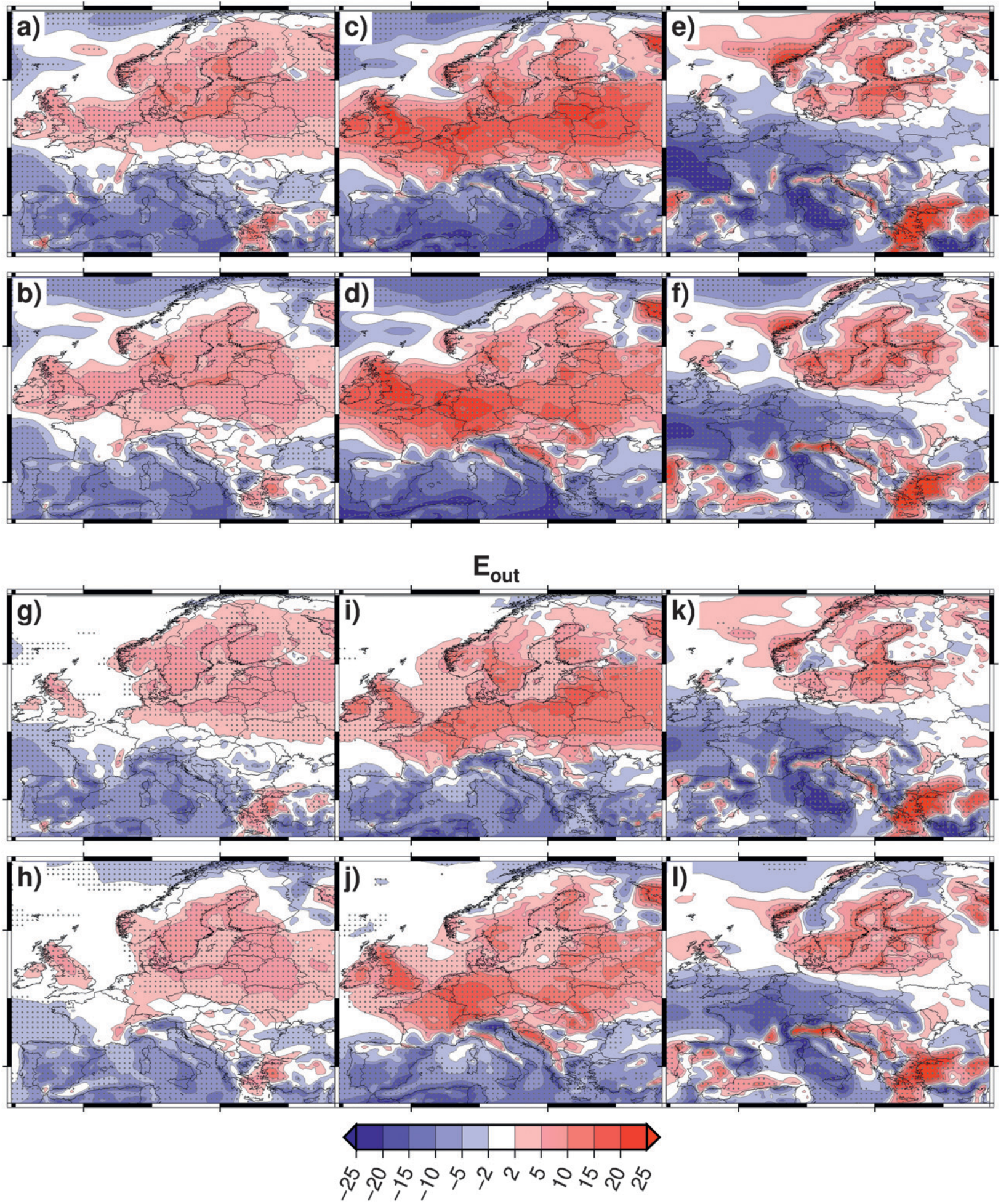

FIG. 3. Changes (\%) in annual mean WED for (a),(c),(e) CCLM and (b),(d),(f) REMO. Also shown are changes (\%) in annual $E_{\text {out }}$ of the sample turbine between the RCMs-A1B and RCMs-20 for (g),(i),(k) CCLM and (h),(j),(l) REMO: (left) all year, (center) winter (DJF), and (right) summer (JJA). Reference periods are 1961-2000 (20C) and 2061-2100 (A1B). Significant changes are dotted (Student's $t$ test, $95 \%$ confidence level). 


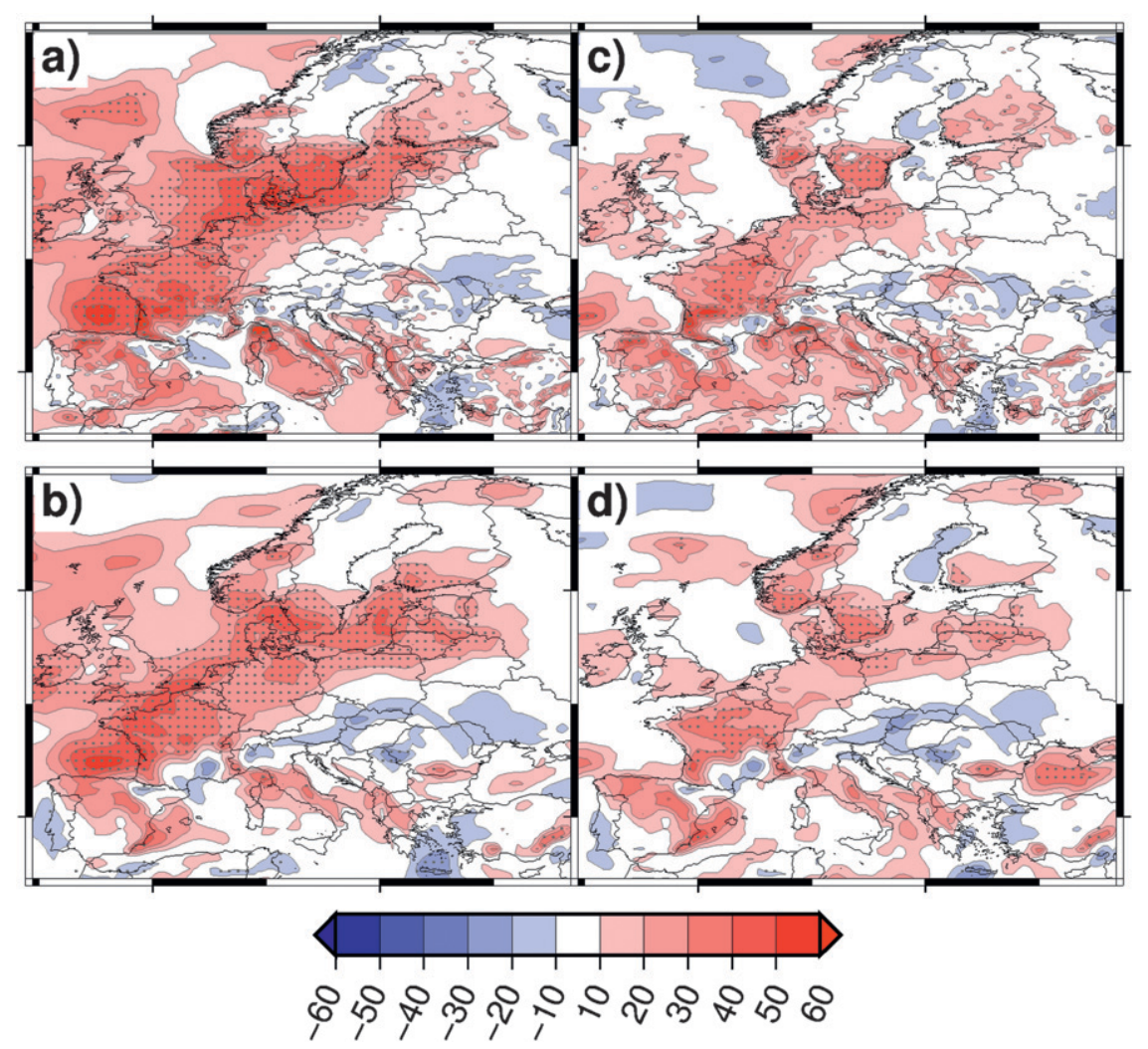

FIG. 4. Changes (\%) in interannual variability of mean WED between the RCMs-A1B and RCMs-20C for (a) CCLM and (b) REMO. (c),(d) As in (a) and (b), but for changes in the interannual variability of $E_{\text {out }}$ of the sample turbine. Reference periods are 1961-2000 (20C) and 2061-2100 (A1B). Significant changes are dotted ( $F$ test, 95\% confidence level).

shows strongest increase in variability over central Europe and the other projects the major increases over northern Europe (not shown). Most of the significant changes projected for the variability of WED (Figs. 4a,b) do not manifest in significant changes in variability of annual $E_{\text {out }}$ (Figs. 4c,d). A significant increase in interannual variability in both RCMs can be found only for limited regions, mainly onshore. These include southern Norway and Sweden, parts of central France, and small areas along the Baltic coast and the southeastern Spanish coast. Here, the alterations in interannual variability are large and range between $+20 \%$ and $+50 \%$. As mentioned in the previous section, the RCMs have difficulties representing the local wind systems, for example, over high orography and areas like the Adriatic and the Aegean Seas. This means that the magnitude of the projected changes in these areas may be under- or overestimated.

\section{Emergence time of projected changes}

In this section, the emergence time of the projected WED changes is analyzed in detail. With this aim, the magnitude of annual and seasonal mean WED for each year in the 140-yr period is quantified for five representative target areas indicated in Fig. 5a. It is assumed that these target areas capture the characteristics of changes in the surrounding region. For these areas, the fluctuations in annual and seasonal mean WED are investigated focusing on decadal variability and long-term trends. The projected changes for the periods 2021-60 and 20612100 are given in Table 5. The most pertinent developments are shown in Figs. 5b-f, where data are presented as $11-y r$ running means. The dashed lines enclose the envelope of \pm one standard deviation around the mean to give an indication of the WED variability within the decade.

As can be seen in Fig. 5b, large decadal fluctuations can be observed in wintertime WED in the German North Sea region (box NS). Nevertheless, a long-term trend can be identified for both RCMs. By 2100, wintertime WED is $20 \%$ above the $20 \mathrm{C}$ mean. The WED increase is statistical significant for both winter and all year for the period 2061-2100 (Table 5). For the 2021-60 period, changes are only statistical significant for the CCLM chain. For the summer, the projections indicate a reduction in WED, which is not statistical significant in 

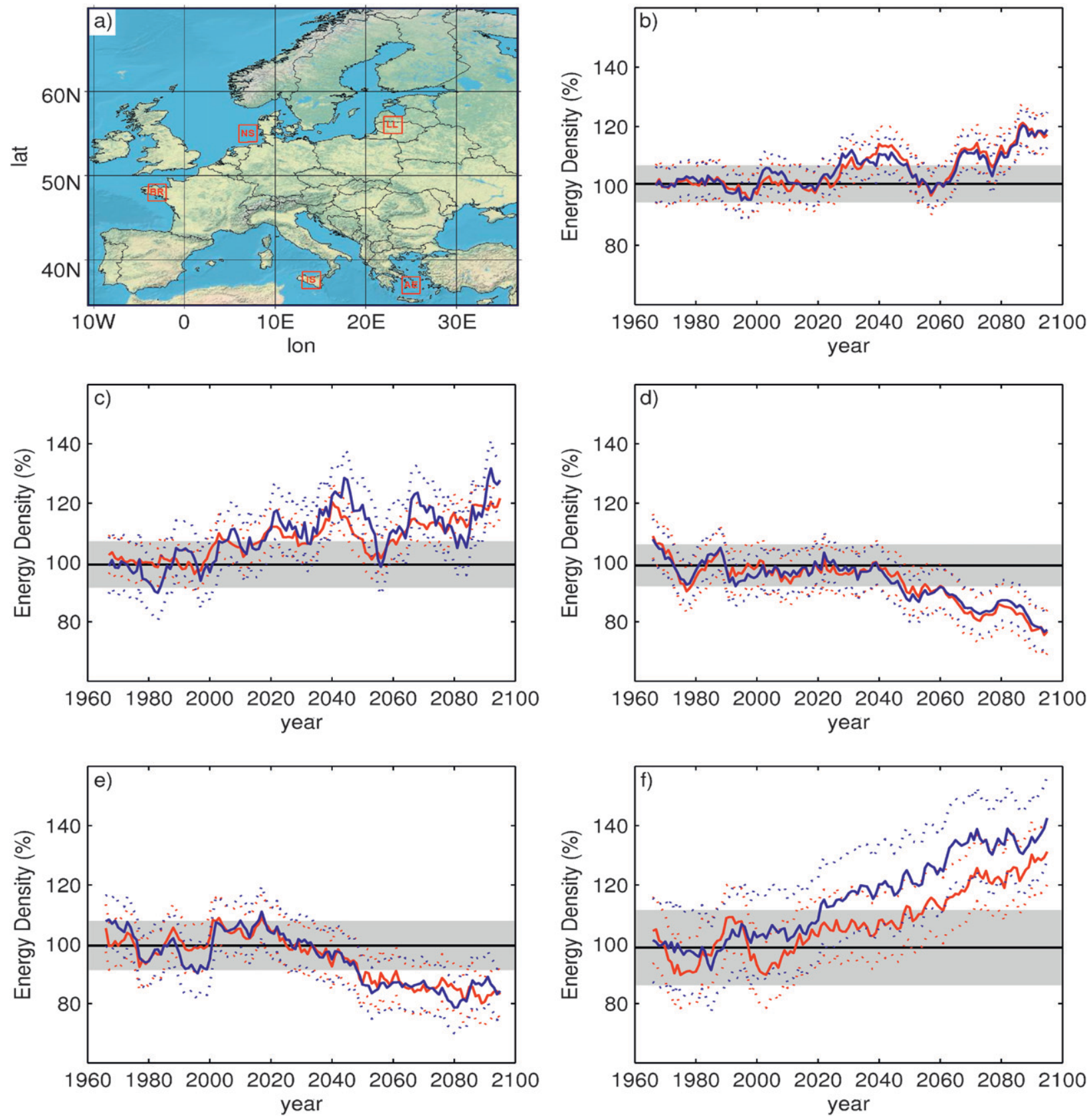

FIG. 5. (a) Area of investigation and selected focus regions in red: NS, LL, BR, IS, and AE. Also shown are the 11-yr running-mean time series of WED for CCLM (blue) and REMO (red) as the deviation from the mean in the RCMs-20C (100\%). The gray area corresponds to the envelope of \pm 1 std dev for current climate Shown are (b) NS and (c) LL for winter and (d) BR, (e) IS, and (f) AE for summer. The solid lines show the ensemble mean projections, and the dashed lines show the envelope of \pm 1 std dev over time.

all cases. Figure 5c depicts winter WED changes over the Baltic States (box LL), which also undergo large decadal fluctuations during the period of investigation. Here, the projected changes are only significant for the period 2061-2100 in the winter season (Table 5). The changes in summer are weak with significant changes only found for REMO in the latter period.
As outlined above, parts of western and central Europe undergo reverse trends in WED in seasonal terms. This is particularly clear for Brittany (box BR), where a noticeable decrease in summertime WED is found after 2040 (Fig. 5d), with significant changes for the period 2061-2100. On the other hand, the winter projections point to a significant increase in WED for the same 
TABLE 5. Relative changes of WED for 2021-60 and 2061-2100 (both A1B) in comparison with current climate conditions (20C, 1961-2000: 100\%) given as the second number following the comma. WED values are averaged for the five target areas NS, LL, $\mathrm{BR}, \mathrm{IS}$, and $\mathrm{AE}$ and are given for the whole year, winter (DJF), and summer (JJA). The exact locations of the areas are given in Fig. 5a. Significant changes are given in boldface font (Student's $t$ test, $95 \%$ confidence level).

\begin{tabular}{|c|c|c|c|c|}
\hline & \multicolumn{2}{|c|}{$2021-60$} & \multicolumn{2}{|c|}{$2061-2100$} \\
\hline & CCLM & REMO & CCLM & REMO \\
\hline \multicolumn{5}{|l|}{ NS } \\
\hline Year & 103,85 & 103,03 & 106,43 & 106,14 \\
\hline Winter & 105,70 & 105,58 & 111, 92 & 112,49 \\
\hline Summer & 96,51 & 94,87 & 96,30 & 98,18 \\
\hline \multicolumn{5}{|l|}{ LL } \\
\hline Year & 105,45 & 104,85 & 109,46 & 108,20 \\
\hline Winter & 109, 77 & 108,65 & 119,96 & 115, 09 \\
\hline Summer & 99,32 & 99,63 & 103,83 & 105,72 \\
\hline \multicolumn{5}{|l|}{ BR } \\
\hline Year & 101,28 & 103,33 & 99,22 & 100,42 \\
\hline Winter & 103,59 & 107, 03 & 109,05 & 112,90 \\
\hline Summer & 94,84 & 95,33 & 83,34 & 81,73 \\
\hline \multicolumn{5}{|l|}{ IS } \\
\hline Year & 93, 37 & 93,62 & 86,31 & 87,27 \\
\hline Winter & 88,92 & 92,34 & 82,04 & 84,10 \\
\hline Summer & 94,32 & 94,49 & 84,00 & 84,42 \\
\hline \multicolumn{5}{|l|}{$\mathrm{AE}$} \\
\hline Year & 105,00 & 101,46 & 111, 37 & 105,76 \\
\hline Winter & 102,08 & 99,24 & 95,15 & 92,70 \\
\hline Summer & 119,35 & 107,95 & 136,30 & 124,16 \\
\hline
\end{tabular}

period, indicating a strong increase of intra-annual variability. In total, the annual changes are very small (see Table 5). For the central Mediterranean (box IS, Fig. 5e), the downward trends in summertime WED exceed the decadal fluctuations during the second half of the twentyfirst century, with a decrease of $-20 \%$. For this area, the decrease of WED is statistically significant for all seasons and for both periods. The exceptional increase in summertime WED in the Aegean (box AE) is reflected in Fig. $5 f$ in a steep increase in WED from the year 2000 onward. WED reaches from $+30 \%$ to $+40 \%$ by 2100 relative to the $20 \mathrm{C}$ mean, with larger changes for CCLM (blue line) than for REMO (red line). This trend in summer WED clearly dominates the annual trends (see Table 5); as for the winter WED, a small decrease is identified for the latter period.

To summarize, distinct long-term trends, which exceed the decadal variability, are identified for several areas especially for winter and summer. In particular, this analysis shows that some long-term trends are already statistically significant in the middle of the twenty-first century. Further, regions like Brittany show significant changes for both seasons of opposite signs, thus indicating an increase in intra-annual variability.

\section{Linkages to alterations in large-scale pressure and circulation patterns}

Some simple considerations help to understand the physical causes of the projected changes in wind energy potential and thus enhance the reliability of the results. A large-scale forcing parameter closely related to regional wind energy is the geostrophic near-surface wind. Over the eastern North Atlantic and parts of western Europe, the large-scale geostrophic wind conditions are largely related with the North Atlantic Oscillation (NAO; Wanner et al. 2001). For example, a recent study analyzed the link between NAO phase and wind energy production for the United Kingdom (Brayshaw et al. 2011). However, the influence of the NAO variability is small over large parts of central, northeastern, and southeastern Europe; thus, the NAO is not a representative proxy for the regional wind conditions in those areas (cf. Wanner et al. 2001; Pinto and Raible 2012). Therefore, we analyze here the changes in MSLP and MSLP gradient in the driving GCM (Fig. 6), independent of whether they are related to NAO variability or they are not related to NAO variability. In particular, we investigate the added value of the RCM simulations relative to the GCM.

During wintertime, ECHAM reveals an intensification of the dominant NAO-related pressure pattern between the Icelandic low and the Azores high (Fig. 6a). MSLP significantly increases farther south along $40^{\circ} \mathrm{N}$, with the largest changes over the central Mediterranean. This indicates an intensification and eastward shift of the Azores high. Consequently, the pressure gradient over the North Atlantic and Europe considerably increases and is slightly shifted northward, associated with an amplification of the pressure gradient over the North Atlantic (between $50^{\circ}$ and $60^{\circ} \mathrm{N}$ ) and the British Isles up to the Baltic region (Fig. 6c).

In summer, MSLP changes are considerably weaker than in winter. MSLP decreases in the subtropics and in high latitudes (Fig. 6b). Over northwestern Europe a significant increase in MSLP is found ranging from the British Isles to Poland. Over the Aegean Sea, a strong decline in MSLP is located east of Crete. Conversely, a localized increase is found over the Middle East, leading to a strengthening of the pressure gradient (Fig. 6d), which then affects the RCM climate change signal. The pressure reductions in the eastern North Atlantic indicate a weakening of the Azores high during summer, which is also somewhat shifted northeastward. This reduces the pressure gradient over western Europe (Fig. 6d). In contrast, an increase in the pressure gradient is found for onshore regions adjoining the Mediterranean Sea in the north. 

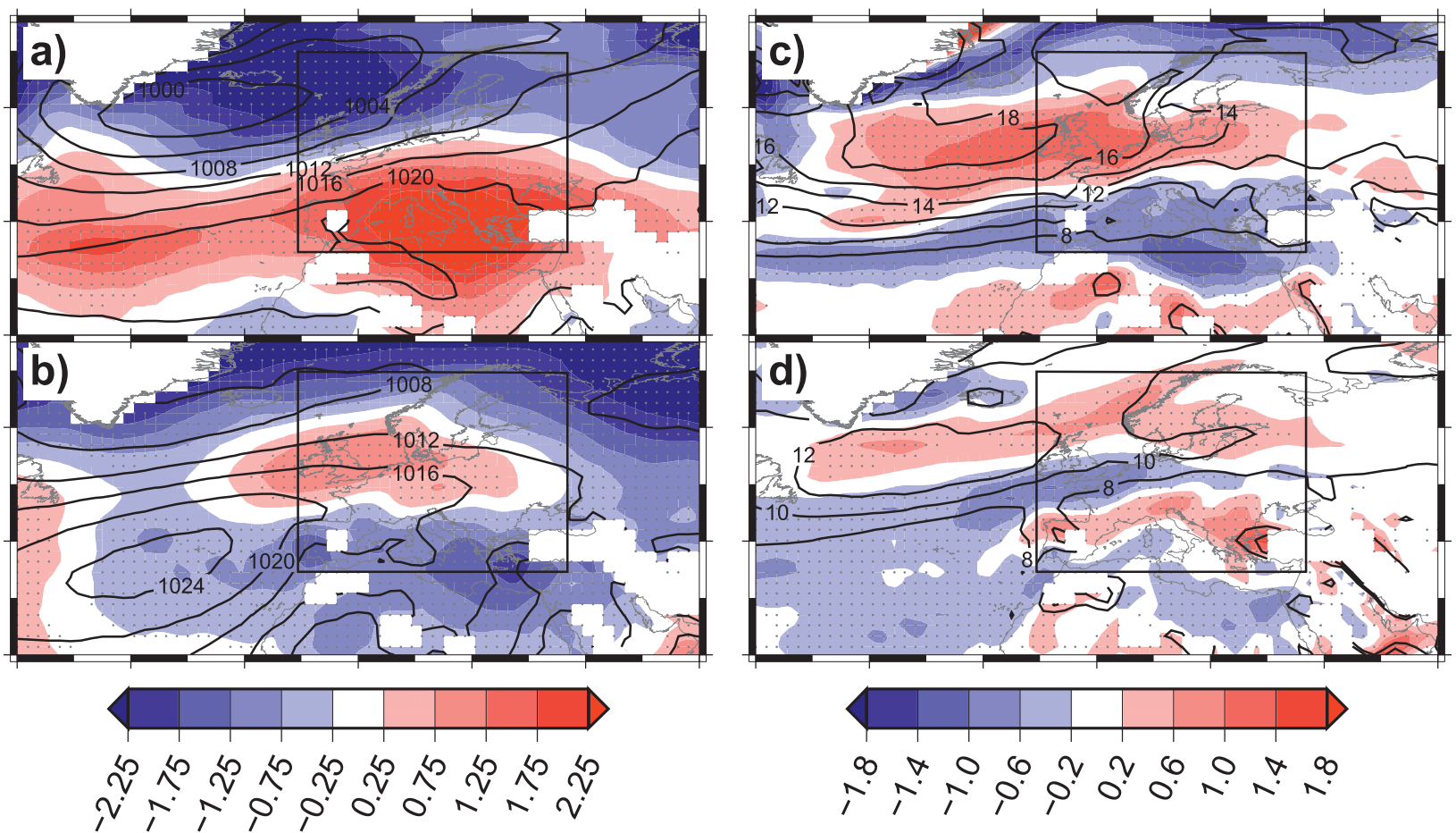

FIG. 6. Long term mean MSLP field for 20C (contours) and changes between A1B and 20C (colors) (hPa) for (a) winter and (b) summer. (c),(d) As in (a),(b), but for the long-term mean large-scale MSLP gradient for 20C (contours) and changes between A1B and 20C (colors) $\left[\mathrm{hPa}(500 \mathrm{~km})^{-1}\right]$. Reference periods are 1961-2000 (20C) and 2061-2100 (A1B). Significant changes are dotted ( $F$ test, $95 \%$ confidence level). MSLP and MSLP gradient values above high orography $(1500 \mathrm{~m})$ are omitted. The black box marks the study region as shown in Figs. 1-4.

Comparing Figs. 3 and 6 provides evidence that the projected changes for the MSLP gradient generally agree qualitatively with the identified alterations in WED. In particular, the driving large-scale factor for increasing wintertime WED in central and northern Europe and decreasing WED in the Mediterranean (Figs. 3c,d) is the northeastward shift and the intensification of the pressure gradient between the Azores high and the Icelandic low (Fig. 6c). Similar to present results for ECHAM, Donat et al. (2010, their Fig. 2) found an intensified pressure gradient across central and western Europe using a multi-GCM ensemble. This suggests that the projected changes for MSLP and wind energy potential are robust regarding different GCMs. Besides the amplified pressure gradient over central Europe, a second factor may contribute to the increase in WED: the northeastward displacement of the westerly winds is closely associated with a shift of the cyclonic activity toward western Europe and more frequent windstorms over the North Sea (Pinto et al. 2007; Löptien et al. 2008; Della-Marta and Pinto 2009). This has probably only contributed in a limited way to $E_{\text {out }}$, as a part of these changes are out of the wind range suitable for wind energy production.
As in wintertime, summertime changes in wind energy potential (Figs. 3e,f) largely correspond to changes in MSLP gradient (Fig. 6d). Bloom et al. (2008) associated the growth in WED in the Aegean with etesian winds that occur in this region during summer. The northwarddirected etesian winds result from a combination of a thermally induced low pressure system over Turkey and high pressure over the Baltic. In the central Mediterranean, RCM-simulated changes in wind energy potential are apparently not completely caused by changes in geostrophic wind. In the RCM simulations, the wind energy potential decreases in most onshore and offshore regions, whereas in ECHAM a reduced (increased) MSLP gradient over the Mediterranean Sea (over onshore regions in southern Europe) is found. One reason for the RCM signal may be a stronger relative influence of local wind systems (e.g., bora, mistral) and thus of the ageostrophic wind component in case of weak geostrophic wind situations.

\section{Summary and conclusions}

The present study provides a Europe-wide analysis of possible changes in wind energy indices under future 
GHG conditions focusing on regional changes. Changes in WED and its interannual and intra-annual variability are estimated using spatial and temporal high-resolution data. Additionally, changes in the energy yield of a sample turbine are assessed for ECHAM-driven RCM projections. Simulations for present climate conditions document that both GCM and RCM chains produce comparable results and are suitable to evaluate potential changes in WED across Europe. The GCM model bias compared to reanalysis data produces considerably stronger uncertainty than the choice of RCM. In contrast to mean WED and $E_{\text {out }}$, the spatial patterns of interannual variability of both variables are less homogeneous between the different model chains.

The projections for the end of the twenty-first century show that changes in annual mean WED are generally small (within a range of $\pm 10 \%$ ). In regional terms, increasing values over northern and central Europe and reductions over the Mediterranean are projected. In seasonal terms, changes are much more substantial: for northern and central Europe, a significant increase in wind energy potential is identified during wintertime. Most of the Mediterranean region may experience a decline in WED, with the largest reductions in winter. In some regions in central Europe (e.g., in northern France and western Germany), the trends are diverse between seasons, with a growth in WED in winter and a reduction in summer. This suggests higher intra-annual variations in WED compared to current climate conditions. Changes in WED manifested also in $E_{\text {out }}$ of the sample turbine; alterations are very similar with regard to spatial extend and sign of change, indicating that they occur partially in the operational range of current wind turbines. However, changes in $E_{\text {out }}$ are somewhat smaller than the alterations in WED, especially in offshore regions, as the remaining changes in the wind climate are beyond the wind speed range of current turbines.

The changes in wind energy potential manifest similarly, but with some spread between both GCM/RCM model chains and the ensemble simulations. The climate change signal is of the same order of magnitude as the GCM-induced model bias. In terms of interannual variability of WED, significant increases in western and northern Europe are projected toward the end of the twenty-first century. Concerning the variability of $E_{\text {out }}$, significant changes are found only over small onshore areas in western Europe (e.g., southern Scandinavia and France). However, these changes are large, reaching up to $+50 \%$, thus indicating a considerable change in interannual variability. In section 5 the emergence time of the long-term trends was analyzed for selected target areas. Results show that, despite the large decadal variability, some long-term trends are already statistically significant in the middle of the twenty-first century. Furthermore, regions like Brittany show significant changes for both seasons of opposite signs, thus clearly indicating an increase also of intra-annual variability of WED.

Many of the observed changes in wind energy indices are connected to alterations in the large-scale MSLP patterns, surface wind, and synoptic activity over the North Atlantic and Europe as simulated by ECHAM. In line with wind energy potential, MSLP changes are largest during wintertime, with an increasing pressure gradient between the Azores high and the Icelandic low. However, especially in summer, no clear link between the change in WED and the change in MSLP can be identified for some areas over the Mediterranean. Here, local effects seem to play a more important role than large-scale geostrophic wind.

The present work suggests a slight increase of wind energy potential over central and northern Europe in future decades. Further, western and central Europe are projected to face not only higher interannual variability, but also a stronger intra-annual variability. This finding is of pivotal importance for the future planning of energy networks toward a reliable energy supply in a panEuropean perspective. On the other hand, southern Europe should be prepared for a reduction in the wind energy potential under future climate conditions, excepted for the Aegean Sea, which is likely to experience an amplification of the annual wind energy potential from increases in summer and autumn. Analysis of the energy yield $E_{\text {out }}$ of a sample turbine indicates that changes in the European wind climate are partly within a velocity range that is important for wind energy generation. Therefore, the changing wind climate-and in particular the higher variability in wind energy resources-should be considered in future strategic planning for the energy networks.

Acknowledgments. We thank the German Federal Environment Agency, the COSMO-CLM consortium and U. Böhm (PIK) for providing COSMO-CLM data, and R. Podzun (MPI for Meteorology, Germany) for producing REMO simulations. We thank C. Moseley (MPI for Meteorology, Germany), P. Ludwig, M. K. Karremann, and D. Yuen (all University of Cologne, Germany) for help with the data processing. Authors R. Haas and J. G. Pinto were supported by the German Federal Ministry of Education and Research (BMBF) under the project Probabilistic Decadal Forecast for Central and Western Europe (MIKLIP-PRODEF, Contract 01LP1120A).

\section{REFERENCES}

Barstad, I., A. Sorteberg, and M. S. Mesquita, 2012: Present and future offshore wind power potential in northern Europe 
based on downscaled global climate runs with adjusted SST and sea ice cover. Renewable Energy, 44, 398-405.

Bloom, A., V. Kotroni, and K. Lagouvardos, 2008: Climate change impact of wind energy availability in the eastern Mediterranean using the regional climate model PRECIS. Nat. Hazards Earth Syst. Sci., 8, 1249-1257.

Brayshaw, D. J., A. Troccoli, R. Fordham, and J. Methven, 2011: The impact of large scale atmospheric circulation patterns on wind power generation and its potential predictability: A case study over the UK. Renewable Energy, 36, 2087-2096.

Dee, D. P., and Coauthors, 2011: The ERA-Interim reanalysis: Configuration and performance of the data assimilation system. Quart. J. Roy. Meteor. Soc., 137, 553-597.

Della-Marta, P. M., and J. G. Pinto, 2009: The statistical uncertainty of changes in winter storms over the North Atlantic and Europe in an ensemble of transient climate simulations. Geophys. Res. Lett., 36, L14703, doi:10.1029/2009GL038557.

Demuzere, M., M. Werner, N. P. M. van Lipzig, and E. Roeckner, 2009: An analysis of present and future ECHAM5 pressure fields using a classification of circulation patterns. Int. J. Climatol., 29, 1796-1810.

Donat, M. G., G. C. Leckebusch, J. G. Pinto, and U. Ulbrich, 2010: European storminess and associated circulation weather types: Future changes deduced from a multi-model ensemble of GCM simulations. Climate Res., 42, 27-43.

EEA, 2009: Europe's onshore and offshore wind energy potential: An assessment of environmental and economic constraints. EEA Tech. Rep. 6/2009, European Environmental Agency, 88 pp.

General Electric, cited 2010: $2.5 \mathrm{MW}$ wind turbine series. GE Brochure GEA17007B, 16 pp. [Available online at http://www.geenergy.com/content/multimedia/_files/downloads/GEA17007AWind25Brochure.pdf.]

Hollweg, H. D., and Coauthors, 2008: Ensemble simulations over Europe with the regional climate model CLM forced with IPCC AR4 global scenarios. CLM Tech. Rep. 3, 152 pp. [Available online at http://www.mad.zmaw.de/fileadmin/extern/documents/ reports/MaD_TechRep3_CLM_1_.pdf.]

IEC, 2005a: Wind turbines-Part 1: Design requirements. International Electrotechnical Commission, IEC 61400-1, 179 pp. , 2005b: Wind turbines-Part 3: Design requirements for offshore wind turbines. International Electrotechnical Commission, IEC 61400-3, $263 \mathrm{pp}$

Jacob, D., 2001: A note to the simulation of the annual and interannual variability of the water budget over the Baltic Sea drainage basin. Meteor. Atmos. Phys., 77, 61-73.

Jungclaus, J. H., and Coauthors, 2006: Ocean circulation and tropical variability in the coupled model ECHAM5/MPI-OM. J. Climate, 19, 3952-3972.

Kjellström, E., G. Nikulin, U. Hansson, G. Strandberg, and A. Ullerstig, 2011: 21st century changes in the European climate: Uncertainties derived from an ensemble of regional climate model simulations. Tellus, 63A, 24-40.

Larsén, X. G., J. Mann, J. Berg, H. Göttel, and D. Jacob, 2010: Wind climate from the regional climate model REMO. Wind Energy, 13, 279-296.

Löptien, U., O. Zolina, S. Gulev, M. Latif, and V. Soloviov, 2008: Cyclone life cycle characteristics over the Northern Hemisphere in coupled. GCMs. Climate Dyn., 31, 507-532.

Manwell, J. F., J. G. McGrown, and A. L. Rogers, 2009: Wind Energy Explained: Theory, Design and Application. 2nd ed. John Wiley and Sons, 704 pp.

Meehl, G., C. Covey, T. Delworth, M. Latif, B. McAvaney, J. Mitchell, R. Stouffer, and K. Taylor, 2007: The WCRP
CMIP3 multimodel dataset: A new era in climate change research. Bull. Amer. Meteor. Soc., 88, 1383-1394.

Moccia, J., A. Arapogianni, J. Wilkes, C. Kjaer, and R. Gruet, 2011: Pure power-Wind energy targets for 2020 and 2030. European Wind Energy Association Rep., 98 pp. [Available online at http://www.ewea.org/fileadmin/files/library/publications/ reports/Pure_Power_III.pdf.]

Nakicenovic, N., and R. Swart, Eds., 2000: Special Report on Emissions Scenarios. Cambridge University Press, 570 pp.

Pinto, J. G., and C. C. Raible, 2012: Past and recent changes in the North Atlantic Oscillation. Wiley Interdiscip. Rev.: Climate Change, 3, 79-90, doi:10.1002/wcc. 150 .

, U. Ulbrich, G. C. Leckebusch, T. Spangehl, M. Reyers, and S. Zacharias, 2007: Changes in storm track and cyclone activity in three SRES ensemble experiments with the ECHAM5/ MPI-OM1 GCM. Climate Dyn., 29, 195-210.

Pryor, S. C., and J. T. Schoof, 2010: Importance of the SRES in projections of climate change impacts on near-surface wind regimes. Meteor. Z., 19, 267-273.

— - - and R. J. Barthelmie, 2005: Empirical downscaling of wind speed probability distributions. J. Geophys. Res., 110, D19109, doi:10.1029/2005JD005899.

$\ldots, \ldots$, and -2006 : Interannual variability of wind indices across Europe. Wind Energy, 9, 27-38.

— R. J. Barthelmie, N. E. Clausen, M. Drews, N. MacKeller, and E. Kjellström, 2012a: Analyses of possible changes in intense and extreme wind speeds over northern Europe under climate change scenarios. Climate Dyn., 38, 189-208.

_ G. Nikulin, and C. Jones, 2012b: Influence of spatial resolution on regional climate model derived wind climates. J. Geophys. Res., 117, D03117, doi:10.1029/2011JD016822.

Räisänen, J., and Coauthors, 2004: European climate in the late twenty-first century: Regional simulations with two driving global models and two forcing scenarios. Climate Dyn., 22, 13-31.

Rockel, B., A. Will, and A. Hense, 2008: The Regional Climate Model COSMO-CLM (CCLM). Meteor. Z., 17, 347-348.

Schönwiese, C. D., 1985: Praktische Statistik für Meteorologen und Geowissenschaftler (Practical Statistics for Meteorologists and Earth Scientists). Borntraeger, 302 pp.

Solomon, S., D. Qin, M. Manning, Z. Chen, M. Marquis, K. Averyt, M. M. B. Tignor, and H. L. Miller Jr., Eds., 2007: Climate Change 2007: The Physical Science Basis. Cambridge University Press, 996 pp.

Steppeler, J., G. Doms, U. Schättler, H. W. Bitzer, A. Gassmann, U. Damrath, and G. Gregoric, 2003: Meso-gamma scale forecasts using the nonhydrostatic model LM. Meteor. Atmos. Phys., 82, 75-96.

Taylor, K. E., R. J. Stouffer, and G. A. Meehl, 2012: An overview of CMIP5 and the experiment design. Bull. Amer. Meteor. Soc., 93, 485-498.

Uppala, S. M., and Coauthors, 2005: The ERA-40 Re-Analysis. Quart. J. Roy. Meteor. Soc., 131, 2961-3012, doi:10.1256/qj.04.176.

Walter, A., and Coauthors, 2006: A high resolution reference data set of German wind velocity 1951-2001 and comparison with regional climate model results. Meteor. Z., 15, 585-596.

Wanner, H., S. Bronnimann, C. Casty, D. Gyalistras, J. Luterbacher, C. Schmutz, D. B. Stephenson, and E. Xoplaki, 2001: North Atlantic Oscillation-Concepts and studies. Surv. Geophys., 22, 321-381.

Wilkes, J., J. Moccia, and M. Dragan, 2012: Wind in power-2011 European statistics. European Wind Energy Association Rep., 11 pp. [Available online at http://www.ewea.org/fileadmin/files/ library/publications/statistics/Wind_in_power_2011_European_ statistics.pdf.] 